\title{
Clinical Study \\ The Association of IL-12b Polymorphisms with Systemic Lupus Erythematosus in Chinese Han Population
}

\author{
Yong Shao, ${ }^{1,2}$ Jie Zhang, ${ }^{1,2}$ Yuewen Chen, ${ }^{1,3}$ Qi Wu, ${ }^{1,3}$ Ming Guan, ${ }^{4}$ Bo Yu, ${ }^{2}$ \\ Jun Wan, ${ }^{1,3,5}$ and Wei Zhang ${ }^{1,3,5}$ \\ ${ }^{1}$ Shenzhen Key Lab for Translational Medicine of Dermatology, Shenzhen PKU-HKUST Medical Center, No. 1120, Lianhua Road, \\ Futian District, Shenzhen, Guangdong 518036, China \\ ${ }^{2}$ Department of Dermatology, Shenzhen Hospital Peking University, Shenzhen, Guangdong 518036, China \\ ${ }^{3}$ Biomedical Research Institute, Shenzhen PKU-HKUST Medical Center, No. 1120, Lian-Hua Road, Fu-Tian District, Shenzhen, \\ Guangdong 510632, China \\ ${ }^{4}$ Department of Clinical Laboratory, Huashan Hospital, Shanghai 200040, China \\ ${ }^{5}$ Division of Life Science, The Hong Kong University of Science and Technology, Hong Kong
}

Correspondence should be addressed to

Jun Wan,wanj@ust.hk and Wei Zhang, zhangweispace@gmail.com

Received 24 January 2012; Accepted 16 March 2012

Academic Editor: Javier Martin

Copyright () 2012 Yong Shao et al. This is an open access article distributed under the Creative Commons Attribution License, which permits unrestricted use, distribution, and reproduction in any medium, provided the original work is properly cited.

Background. Systemic lupus erythematosus (SLE) is a complex immune disease. The genetic variation in the IL-12b gene was found to associate with SLE in Caucasian population. In this study, we examined this association in Chinese Han population by a recently developed method, unlabeled probe-based high resolution melting analysis. Methods. A total of 297 SLE patients and 351 controls were recruited. Unlabeled probe-based high resolution melting analysis (HRMA) was used in genotyping. Results. Statistically significant differences were observed in both genotype and allele frequencies for rs6887695 in the SLE patients as compared with the controls. Minor allele (C) of rs6887695 ( $P=0.031$, OR 0.78, [95\% CI 0.63-0.98]) was found to be protective against SLE. The association of SNP rs6887695 with the diagnostic criteria of SLE was also examined. Minor allele (C) exerts protective effect on the incidence of arthritis $(P=0.013, \mathrm{OR}=0.65,95 \% \mathrm{CI}=0.47-0.92)$ and abnormalities of antinuclear antibody $(P=0.022$, $\mathrm{OR}=0.68,95 \% \mathrm{CI}=0.49-0.95)$. IL-12b SNPs were irrelevant to other diagnostic criteria of SLE. Summary. Polymorphisms of rs6887695 in IL-12b gene were associated with disease risk, as well as arthritis and antinuclear antibody synthesis, of systemic lupus erythematosus in Chinese population.

\section{Introduction}

Interleukin-12 (IL-12) is a heterodimeric cytokine that is produced during innate immune response by monocytes, macrophages, dendritic cells (DCs), neutrophils, and B cells $[1,2]$. The general function of IL-12 is thought to be as an important immunomodulator linking innate recognition of pathogens to development of adaptive immune response $[1,3]$. Interleukin (IL-12b), also known as p40, is one of the components of IL-12 which covalently combine with p35 (IL-12a) to form mature IL-12 protein. Otherwise, IL$12 \mathrm{~b}$ could also interact with p19 (IL-23a) to form the other IL-12 family member, IL-23. IL-23 has strong capacity of induction of a novel subset of $\mathrm{T}$ cells, the T-helper-17 (Th17) cells. These novel T-helper cells are characterized by production of IL-17 cytokine which is strongly implicated in the pathophysiology of various autoimmune diseases [4]. Owing to the important role of IL-12 and IL-23 during the immune response, IL-12b, the common component of IL12 and IL-23, might be a candidate gene of autoimmune disease. Indeed, IL-12b has been found to associate with several autoimmune diseases including psoriasis, rheumatoid arthritis, and type 1 diabetes [5-9].

Systemic lupus erythematosus (SLE) is a complex autoimmune disease with multiple organs affected. Autoantibody production, formation of immune complexes and 
TABLE 1: Genotype and allele frequencies of IL-12b SNP rs6887695 in SLE cases and controls*.

\begin{tabular}{|c|c|c|c|c|c|c|c|c|c|}
\hline \multirow[b]{2}{*}{$\begin{array}{l}\text { SNP, } \\
\text { population }\end{array}$} & \multirow[b]{2}{*}{$\begin{array}{c}\text { No. of } \\
\text { subjects }\end{array}$} & \multicolumn{3}{|c|}{ Genotype frequency, no. (\%) } & \multicolumn{4}{|c|}{ Allele frequency, no. (\%) } & \multirow[b]{2}{*}{ OR $(95 \% \mathrm{CI})$} \\
\hline & & $\begin{array}{c}\text { Major } \\
\text { homozygote }\end{array}$ & $\begin{array}{l}\text { Hetero- } \\
\text { zygote }\end{array}$ & $\begin{array}{c}\text { Minor } \\
\text { homozygote }\end{array}$ & $P$ & $\begin{array}{c}\text { Major } \\
\text { allele }\end{array}$ & $\begin{array}{c}\text { Minor } \\
\text { allele }\end{array}$ & $P$ & \\
\hline $\begin{array}{l}\text { Genotype } \\
\text { or allele }\end{array}$ & & GG & GC & CC & & G & $\mathrm{C}$ & & \\
\hline Cases & 297 & $107(36.0)$ & $153(51.5)$ & $37(12.5)$ & \multirow{2}{*}{0.019} & $367(61.8)$ & $227(38.2)$ & \multirow{2}{*}{0.031} & \multirow{2}{*}{$0.78(0.63-0.98)$} \\
\hline Controls & 351 & $114(32.5)$ & $164(46.7)$ & $73(20.8)$ & & $392(55.8)$ & $310(44.2)$ & & \\
\hline
\end{tabular}

* SNP: single-nucleotide polymorphism; SLE: systemic lupus erythematosus; OR: odds ratios; 95\% CI: 95\% confidence interval.

TABLE 2: Association of IL-12b SNP rs6887695 with clinical symptoms in SLE patients*.

\begin{tabular}{|c|c|c|c|c|c|c|c|c|c|}
\hline \multirow[b]{2}{*}{$\begin{array}{l}\text { SNP, } \\
\text { population }\end{array}$} & \multirow[b]{2}{*}{$\begin{array}{c}\text { No. of } \\
\text { subjects }\end{array}$} & \multicolumn{3}{|c|}{ Genotype frequency, no. (\%) } & \multirow[b]{2}{*}{$P$} & \multicolumn{3}{|c|}{ Allele frequency, no. (\%) } & \multirow[b]{2}{*}{ OR (95\% CI) } \\
\hline & & $\begin{array}{c}\text { Major } \\
\text { homozygote }\end{array}$ & $\begin{array}{c}\text { Hetero- } \\
\text { zygote }\end{array}$ & $\begin{array}{c}\text { Minor } \\
\text { homozygote }\end{array}$ & & $\begin{array}{c}\text { Major } \\
\text { allele }\end{array}$ & $\begin{array}{c}\text { Minor } \\
\text { allele }\end{array}$ & $P$ & \\
\hline $\begin{array}{l}\text { Genotype } \\
\text { or allele }\end{array}$ & & GG & GC & $\mathrm{CC}$ & & G & $\mathrm{C}$ & & \\
\hline Total cases & 297 & 107 & 153 & 37 & & 367 & 227 & & \\
\hline \multicolumn{10}{|l|}{ Rash } \\
\hline Positive & 161 & 59 & 83 & 19 & \multirow{2}{*}{0.923} & 201 & 121 & \multirow{2}{*}{0.728} & \multirow{2}{*}{$0.94(0.68-1.31)$} \\
\hline Negative & 136 & 48 & 70 & 18 & & 166 & 106 & & \\
\hline \multicolumn{10}{|c|}{ Photosensitivity } \\
\hline Positive & 90 & 32 & 47 & 11 & \multirow{2}{*}{0.987} & 111 & 69 & \multirow{2}{*}{0.969} & \multirow{2}{*}{$1.01(0.70-1.44)$} \\
\hline Negative & 207 & 75 & 106 & 26 & & 256 & 158 & & \\
\hline \multicolumn{10}{|l|}{ Arthritis } \\
\hline Positive & 181 & 74 & 90 & 17 & \multirow{2}{*}{0.033} & 238 & 124 & \multirow{2}{*}{0.013} & \multirow{2}{*}{$0.65(0.47-0.92)$} \\
\hline Negative & 116 & 33 & 63 & 20 & & 129 & 103 & & \\
\hline \multicolumn{10}{|l|}{ Oral ulcer } \\
\hline Positive & 74 & 27 & 39 & 8 & \multirow{2}{*}{0.884} & 93 & 55 & \multirow{2}{*}{0.761} & \multirow{2}{*}{$0.94(0.64-1.38)$} \\
\hline Negative & 223 & 80 & 114 & 29 & & 274 & 172 & & \\
\hline
\end{tabular}

* SNP: single-nucleotide polymorphism; SLE: systemic lupus erythematosus; OR: odds ratios; 95\% CI: 95\% confidence interval.

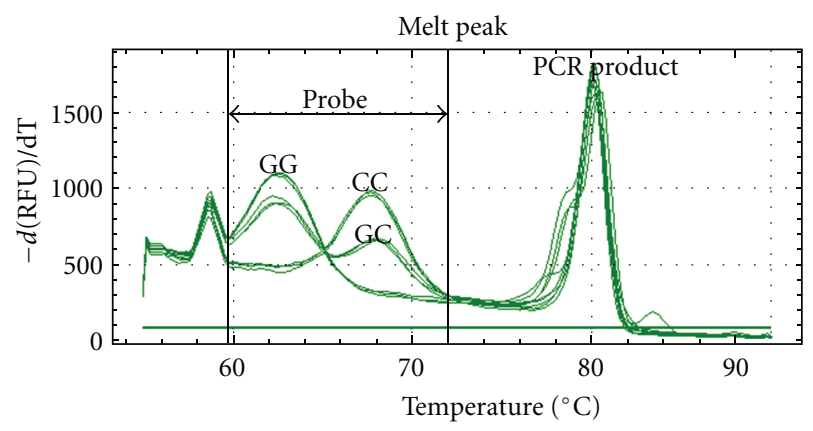

Figure 1: Derivative melting curves of unlabeled probes and amplicon for genotyping of SNP rs6887695. Three genotypes (GG, GC and CC) were discriminated as indicated in probe region.

tissue inflammation are the major clinical features of SLE. The reported prevalence of SLE is 20 to 150 cases per 100,000 with a female/male ratio of $9: 1[10,11]$. The etiology of SLE has not been completely understood, but it is well known that both genetic components and environmental factors contribute to the pathogenesis of SLE [12, 13]. Recently, a series of genome-wide association studies (GWAS) were employed for identifying SLE associated genetic variants [14-19]. These studies provided new insights into the understanding of this complex disease. In the Caucasian populations, it has been suggested that a polymorphism rs6887695 located on IL12B gene was associated with SLE [19]. Here, we examined this association in Chinese Han population by a recently developed method, unlabeled probe-based high-resolution melting analysis.

\section{Methods}

2.1. Patients. A total of 297 patients ( 27 males and 270 females; median age 29 years, range 12-55) who fulfilled the American College of Rheumatology criteria for SLE [20] and 351 ethnically matched healthy controls ( 31 males and 320 females; median age 28 years, range 17-46) were recruited from Shenzhen Hospital, Peking University. The control group had neither family history nor symptoms related to SLE. The study was approved by the institutional review board of the Shenzhen Hospital, and written informed consent was taken from all patients. 
TABLE 3: Association of IL-12b SNP rs6887695 with laboratory parameters in SLE patients*.

\begin{tabular}{|c|c|c|c|c|c|c|c|c|c|}
\hline \multirow[b]{2}{*}{$\begin{array}{l}\text { SNP, } \\
\text { population }\end{array}$} & \multirow[b]{2}{*}{$\begin{array}{l}\text { No. of } \\
\text { subjects }\end{array}$} & \multicolumn{3}{|c|}{ Genotype frequency, no. (\%) } & \multicolumn{4}{|c|}{ Allele frequency, no. (\%) } & \multirow[b]{2}{*}{ OR $(95 \% \mathrm{CI})$} \\
\hline & & $\begin{array}{c}\text { Major } \\
\text { homozygote }\end{array}$ & $\begin{array}{c}\text { Hetero- } \\
\text { zygote }\end{array}$ & $\begin{array}{c}\text { Minor } \\
\text { homozygote }\end{array}$ & $P$ & $\begin{array}{c}\text { Major } \\
\text { allele }\end{array}$ & $\begin{array}{c}\text { Minor } \\
\text { allele }\end{array}$ & $P$ & \\
\hline $\begin{array}{l}\text { Genotype } \\
\text { or allele }\end{array}$ & & GG & GC & CC & & G & $\mathrm{C}$ & & \\
\hline Total cases & 297 & 107 & 153 & 37 & & 367 & 227 & & \\
\hline \multicolumn{10}{|l|}{$\begin{array}{l}\text { Hematological } \\
\text { disorders }\end{array}$} \\
\hline Positive & 187 & 63 & 98 & 26 & \multirow{2}{*}{0.429} & 224 & 150 & \multirow{2}{*}{0.216} & \multirow{2}{*}{$1.24(0.88-1.76)$} \\
\hline Negative & 110 & 44 & 55 & 11 & & 143 & 77 & & \\
\hline \multicolumn{10}{|l|}{ Proteinuria } \\
\hline$\geq 0.5 \mathrm{~g} / 24 \mathrm{~h}$ & 101 & 35 & 52 & 14 & \multirow{2}{*}{0.851} & 122 & 80 & \multirow{2}{*}{0.617} & \multirow{2}{*}{$1.09(0.77-1.55)$} \\
\hline$<0.5 \mathrm{~g} / 24 \mathrm{~h}$ & 196 & 72 & 101 & 23 & & 245 & 147 & & \\
\hline \multicolumn{10}{|l|}{$\begin{array}{l}\text { Antinuclear } \\
\text { antibody }\end{array}$} \\
\hline$\geq 1: 320$ & 168 & 67 & 87 & 14 & \multirow{2}{*}{0.032} & 221 & 115 & \multirow{2}{*}{0.022} & \multirow{2}{*}{$0.68(0.49-0.95)$} \\
\hline$<1: 320$ & 129 & 40 & 66 & 23 & & 146 & 112 & & \\
\hline \multicolumn{10}{|l|}{ Anti-DNA } \\
\hline Positive & 189 & 72 & 97 & 20 & \multirow{2}{*}{0.352} & 241 & 137 & \multirow{2}{*}{0.191} & \multirow{2}{*}{$0.80(0.57-1.12)$} \\
\hline Negative & 108 & 35 & 56 & 17 & & 126 & 90 & & \\
\hline \multicolumn{10}{|l|}{ Anti-nRNP } \\
\hline Positive & 81 & 31 & 41 & 9 & \multirow{2}{*}{0.846} & 103 & 59 & \multirow{2}{*}{0.581} & \multirow{2}{*}{$0.90(0.62-1.31)$} \\
\hline Negative & 216 & 76 & 112 & 28 & & 264 & 168 & & \\
\hline \multicolumn{10}{|l|}{ Anti-Smith } \\
\hline Positive & 68 & 24 & 37 & 7 & \multirow{2}{*}{0.783} & 85 & 51 & \multirow{2}{*}{0.845} & \multirow{2}{*}{$0.96(0.65-1.43)$} \\
\hline Negative & 229 & 83 & 116 & 30 & & 282 & 176 & & \\
\hline $\begin{array}{l}\text { Anti-Ro } \\
\text { (SSA) }\end{array}$ & & & & & & & & & \\
\hline Positive & 118 & 43 & 61 & 14 & 0.968 & 147 & 89 & 0.837 & $0.97(0.69-1.35)$ \\
\hline Negative & 179 & 64 & 92 & 23 & 0.968 & 220 & 138 & 0.831 & $0.97(0.69-1.35)$ \\
\hline $\begin{array}{l}\text { Anti-La } \\
\text { (SSB) }\end{array}$ & & & & & & & & & \\
\hline Positive & 72 & 25 & 38 & 9 & 0.963 & 88 & 56 & 0.848 & $1.04(0.71-1.53)$ \\
\hline Negative & 225 & 82 & 115 & 28 & 0.903 & 279 & 171 & & $1.04(0 . / 1-1.05)$ \\
\hline $\mathrm{C} 3$ and $\mathrm{C} 4$ & & & & & & & & & \\
\hline Decrease & 133 & 49 & 79 & 15 & 0399 & 177 & 109 & 0.960 & $0.99(0.71-1.38)$ \\
\hline Normal & 164 & 58 & 74 & 22 & 0.399 & 190 & 118 & 0.900 & $0.99(0 . / 1-1.08)$ \\
\hline
\end{tabular}

${ }^{*}$ SNP: single-nucleotide polymorphism; SLE: systemic lupus erythematosus; OR: odds ratios; 95\% CI: 95\% confidence interval.

2.2. Genotyping. Genomic DNA was isolated from peripheral blood cells by using Innogent genomic DNA extraction kit (Innogent, China) according to manufactory instruction. Genotyping was assayed by high-resolution melting with unlabeled probe as previously described [21]. Briefly, asymmetric PCR reaction was performed in a volume of $20 \mu \mathrm{L}$ containing $20 \mathrm{ng}$ of genomic DNA, $1 \times$ PCR buffer (Takara, Japan), $200 \mu \mathrm{M}$ dNTPs, $0.5 \mathrm{U}$ rTaq DNA polymerase (Takara, Japan), $0.05 \mu \mathrm{M}$ forward primer, $0.5 \mu \mathrm{M}$ excess reverse primer, and $0.5 \mu \mathrm{M}$ C3-block probe. The PCR reactions were performed in an S1000 Thermal Cycler (Bio-Rad, USA); the conditions included an initial denaturation at $94^{\circ} \mathrm{C}$ for $2 \mathrm{~min}$, followed by 45 cycles of $94^{\circ} \mathrm{C}$ for $30 \mathrm{~s}, 55^{\circ} \mathrm{C}$ for $30 \mathrm{~s}$, and $72^{\circ} \mathrm{C}$ for $20 \mathrm{~s}$ and a final extension at $72^{\circ} \mathrm{C}$ for 5 minutes. The $10 \mu \mathrm{L}$ of PCR products was supplied with $1 \mu \mathrm{L}$ EvaGreen (Bio-Rad, USA) and then subjected to HRM in CFX96 realtime system C1000 Thermal Cycler (Bio-Rad, USA). The samples were first denatured at $95^{\circ} \mathrm{C}$ for $30 \mathrm{~s}$ and rapidly cooled to $40^{\circ} \mathrm{C}$ for $30 \mathrm{~s}$ and then melted from $55^{\circ} \mathrm{C}$ to $90^{\circ} \mathrm{C}$ with a $0.3^{\circ} \mathrm{C} / \mathrm{s}$ ramp rate. Melting curves were analyzed with Bio-Rad Precision Melt Analysis software (Bio-Rad, USA). The sequences of the primers for rs6887695 were as follows: forward 5' - GGT AAG TCA GTT TGA GAG AAG CA -3', reverse $5^{\prime}$ - CTA GGT CAC AAG CGT AGT AAA TG - $3^{\prime}$, and unlabeled C3-blocked probe $5^{\prime}$ - TGT AGT GTA GTG GTC AAT AGT CTG GAT TT $-3^{\prime}$. 


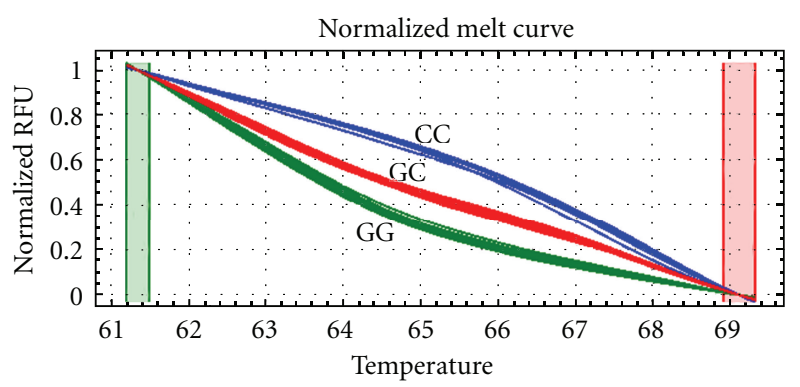

(a)

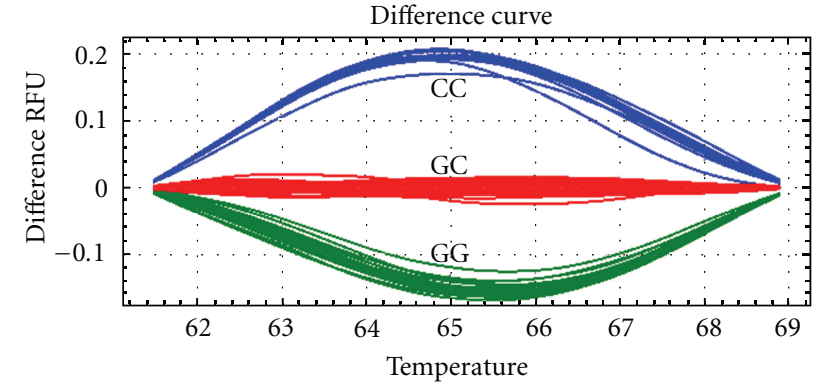

(b)

FIGURE 2: Normalized melting curves and difference curves of unlabeled probe region for genotyping of SNP rs6887695. (a) The melting curve was presented after normalization. Wild type GG genotype showed the lowest melting temperature since there was completely mismatch between the unlabeled probe and wild type. (b) The difference curves were obtained by subtracting each curve from one heterozygote (GC) curve. Three genotypes (GG, GC, and CC) were shown as indicated.

2.3. Statistical Analysis. The SNP was analyzed for an association with the disease by means of comparison of the minor allele frequency (MAF) in patients and controls as well as the constancy of Hardy-Weinberg equilibrium using chi square test or Fisher's exact test. The magnitude of association was expressed as odds ratio (OR) with a $95 \%$ confidence interval ( $95 \% \mathrm{CI}) . P$ values less than 0.05 were considered statistically significant.

\section{Results}

3.1. High-resolution Melting Analysis (HRMA) with Unlabeled Probe. High-resolution melting analysis with unlabeled C3blocked probe was used for genotyping. As shown in Figure 1, three genotypes (GG, GC, and CC) of SNP rs6887695 $(\mathrm{G}>\mathrm{C})$ were accurately distinguished by the derivative melting curves in the probe region. The derivative melting curves directly from the PCR products were not able to distinguish these genotypes (Figure 1, right part), and the sensitivity and accuracy of HRMA were dramatically improved using unlabeled probes (Figure 1, left part). After further analyzing on the normalized melting unlabeled probe region, we were able to discriminate all the genotypes clearly (Figure 2(a)). The difference curves generated by subtracting of one heterozygote curve displayed a much more clear view for genotype discrimination (Figure 2(b)). Then, this method was employed to screen our samples in the present study.

3.2. Association of SNP rs6887695 with SLE. Table 1 shows IL-12b rs6887695 genotype and allele frequencies in SLE patients and healthy controls. Genotype frequencies were in Hardy-Weinberg equilibrium in the patients and controls. Statistically significant differences were observed in both genotype and allele frequencies for rs6887695 in the SLE patients as compared with the controls. Minor alleles of rs6887695 ( $P=0.031$, OR 0.78, [95\% CI 0.63-0.98]) were found to be protective against SLE.

3.3. Association of SNP rs6887695 with the Diagnostic Criteria of SLE. In order to further analyze the possible significance of IL-12b SNPs in SLE, we compared the genotype and allele frequencies of rs6887695 in different diagnostic criteria of SLE. Among the 11 criteria, serositis and neurological disorders in our study were in low incidence and thus were not subjected to statistical analysis.

Table 2 showed the analysis of IL-12b SNPs with the clinical symptoms of SLE. We found that rs6887695 was associated with the incidence of arthritis $(P=0.033)$, and minor alleles $(\mathrm{C})$ was protective against arthritis $(P=0.013$, $\mathrm{OR}=0.65,95 \% \mathrm{CI}=0.47-0.92$ ). No obvious association was observed between IL-12b SNPs and the incidence of other clinical symptoms.

Table 3 showed the association of IL-12b SNPs with the laboratory parameters of SLE. Interestingly, IL-12b SNPs were associated with antinuclear antibody $(P=0.032)$. Minor alleles (C) of rs6887695 were found to exert protective effect on the abnormalities of antinuclear antibody $(P=$ 0.022, OR $=0.68,95 \% \mathrm{CI}=0.49-0.95)$. IL-12b SNPs were irrelevant to other laboratory parameters of SLE.

\section{Discussion}

Genotyping is an elementary method for SNP analysis. High-resolution melting analysis (HRMA) is a cost-effective and high throughput method for SNP genotyping [2224]. However, it is sometimes difficult to distinguish SNPs of $\mathrm{A} / \mathrm{T}$ or $\mathrm{G} / \mathrm{C}$ (G/C in our case), which make up about $16 \%$ of human SNPs, because such SNPs cause only almost undetectable $\mathrm{Tm}$ shift (less than $0.4^{\circ} \mathrm{C}$ ). Unlabeled probe melting analysis is a modified HRMA in which a $\sim 30 \mathrm{bp} \mathrm{C3-}$ blocked probe is used to target the SNP of interest during the melting. A single-base-pair difference in such a short probe could result in a significant $\mathrm{Tm}$ shift (e.g., $3-4^{\circ} \mathrm{C}$ ). As shown in our study, we can discriminate almost all the SNPs in a more accurate and reliable manner using unlabeled probe melting analysis. Thus, the technology of HRMA with unlabeled probe is strongly recommended for studying genetic components of complex diseases such as SLE.

The association of IL-12b with several autoimmune diseases has been well revealed [5-9]. SLE is a typical chronic autoimmune disease caused by dysregulation of immune 
system. As a common subunit of IL-12 and IL-23, IL$12 \mathrm{~b}$ could participate in regulation of several important autoimmune responses especially in Th1 cell maturation and Th17 cell development $[1,4]$. However, there is little evidence to suggest that IL-12b was associated with disease risk of SLE up to now. In present study, we confirmed that SNP rs6887695 in the gene IL-12b was associated with SLE in the Mainland Chinese Han population, which replicated the findings from a GWAS study in Caucasian population [19], while in a previous study, two SNPs located in the promoter and 3'UTR region of IL-12b gene, respectively, exhibited no association with the susceptibility of SLE in Spanish population [25]. The discrepancy in these findings may be explained by the fact that different SNPs located on IL-12b gene were examined in these studies. The SNP rs6887695 was reported to be associated with psoriasis which is also caused by dysregulation of autoimmune system [9]. Exploring the association of IL-12b with disease risk of SLE in our and others' work could provide us with a common genetic background for autoimmune disease.

In this study, we also analyzed the association of SNP rs6887695 with different diagnostic criteria of SLE. The potential role of rs6887695 in SLE was further proved by its association with some of the clinical symptoms (arthritis) and laboratory parameters (antinuclear antibody) of SLE. The minor allele $(\mathrm{C})$ of rs6887695 was found to be protective against such diagnostic criteria, indicating the aspects through which rs6887695 exerts protective effect on the risk of SLE. This also implies that, at least in Chinese mainland population, rs6887695 in IL-12b gene may not only be a risk factor specific to SLE, but also might be a contributor to the severity of this autoimmune disease. However, it is not clear why rs6887695 has association with such particular parameters. In the future, the underlying mechanism of rs6887695 in SLE or other autoimmune diseases remains to be more extensively studied.

\section{Authors' Contribution}

Y. Shao and J. Zhang contributed equally to this work. B. Yu, J. Wan, and W. Zhang contributed equally to this work.

\section{Conflict of Interests}

The authors declare that there are no conflict of interests.

\section{Acknowledgments}

The study was supported by the Research Grants of Shenzhen-Hong Kong Technological Cooperation. The authors thank Shenzhen Biomedical Research Support Platform for the technical help.

\section{References}

[1] G. Trinchieri, "Interleukin-12 and the regulation of innate resistance and adaptive immunity," Nature Reviews Immunology, vol. 3, no. 2, pp. 133-146, 2003.
[2] G. Trinchieri, "Interleukin-12: a cytokine produced by antigen-presenting cells with immunoregulatory functions in the generation of t-helper cells type 1 and cytotoxic lymphocytes," Blood, vol. 84, no. 12, pp. 4008-4027, 1994.

[3] J. Chehimi and G. Trinchieri, "Interleukin-12: a bridge between innate resistance and adaptive immunity with a role in infection and acquired immunodeficiency," Journal of Clinical Immunology, vol. 14, no. 3, pp. 149-161, 1994.

[4] E. Bettelli, M. Oukka, and V. K. Kuchroo, "TH-17 cells in the circle of immunity and autoimmunity," Nature Immunology, vol. 8, no. 4, pp. 345-350, 2007.

[5] J. Varade, J. Ramon Lamas, L. Rodriguez, M. FernandezArquero, and E. Loza-Santamaria, "IL23R and IL12B genes: susceptibility analysis in rheumatoid arthritis," Annals of the Rheumatic Diseases, vol. 68, no. 7, pp. 1230-1232, 2009.

[6] J. M. Yang, S. Nagasaka, T. Yatagai et al., "Interleukin-12p40 gene (IL-12B) polymorphism and type 1 diabetes mellitus in Japanese: possible role in subjects without having high-risk HLA haplotypes," Diabetes Research and Clinical Practice, vol. 71, no. 2, pp. 164-169, 2006.

[7] Y. T. Chang, C. T. Chou, C. W. Yu et al., "Cytokine gene polymorphisms in Chinese patients with psoriasis," British Journal of Dermatology, vol. 156, no. 5, pp. 899-905, 2007.

[8] K. C. Duffin, J. Woodcock, and G. G. Krueger, "Genetic variations associated with psoriasis and psoriatic arthritis found by genome-wide association," Dermatologic Therapy, vol. 23, no. 2, pp. 101-113, 2010.

[9] R. P. Nair, A. Ruether, P. E. Stuart et al., "Polymorphisms of the IL12B and IL23R genes are associated with psoriasis," Journal of Investigative Dermatology, vol. 128, no. 7, pp. 1653-1661, 2008.

[10] G. J. Pons-Estel, G. S. Alarcon, L. Scofield, L. Reinlib, and G. S. Cooper, "Understanding the epidemiology and progression of systemic lupus erythematosus," Seminars in Arthritis and Rheumatism Journal, vol. 39, no. 4, pp. 257-268, 2010.

[11] M. Gaubitz, "Epidemiology of connective tissue disorders," Rheumatology, vol. 45, supplement 3, pp. iii3-iii4, 2006.

[12] C. J. Edwards and C. Cooper, "Early environmental exposure and the development of lupus," Lupus, vol. 15, no. 11, pp. 814$819,2006$.

[13] S. R. Block, J. B. Winfield, and M. D. Lockshin, "Studies of twins with systemic lupus erythematosus. a review of the literature and presentation of 12 additional sets," American Journal of Medicine, vol. 59, no. 4, pp. 533-552, 1975.

[14] J. B. Harley, M. E. Alarcón-Riquelme, L. A. Criswell et al., "Genome-wide association scan in women with systemic lupus erythematosus identifies susceptibility variants in ITGAM, PXK, KIAA1542 and other loci," Nature Genetics, vol. 40, no. 2, pp. 204-210, 2008.

[15] G. Hom, R. R. Graham, B. Modrek et al., "Association of systemic lupus erythematosus with C8orf13-BLK and ITGAMITGAX," The New England Journal of Medicine, vol. 358, no. 9, pp. 900-909, 2008.

[16] S. V. Kozyrev, A. K. Abelson, J. Wojcik et al., "Functional variants in the B-cell gene BANK1 are associated with systemic lupus erythematosus," Nature Genetics, vol. 40, no. 2, pp. 211216, 2008.

[17] R. R. Graham, C. Cotsapas, L. Davies et al., "Genetic variants near TNFAIP3 on 6q23 are associated with systemic lupus erythematosus," Nature Genetics, vol. 40, no. 9, pp. 1059-1061, 2008.

[18] J. W. Han, H. F. Zheng, Y. Cui et al., "Genome-wide association study in a Chinese han population identifies nine new 
susceptibility loci for systemic lupus erythematosus," Nature Genetics, vol. 41, no. 11, pp. 1234-1237, 2009.

[19] V. Gateva, J. K. Sandling, G. Hom et al., "A large-scale replication study identifies TNIP1, PRDM1, JAZF1, UHRF1BP1 and IL10 as risk loci for systemic lupus erythematosus," Nature Genetics, vol. 41, no. 11, pp. 1228-1233, 2009.

[20] M. C. Hochberg, "Updating the American college of rheumatology revised criteria for the classification of systemic lupus erythematosus," Arthritis \& Rheumatism, vol. 40, no. 9, p. $1725,1997$.

[21] J. Montgomery, C. T. Wittwer, R. Palais, and L. Zhou, "Simultaneous mutation scanning and genotyping by highresolution DNA melting analysis," Nature Protocols, vol. 2, no. 1, pp. 59-66, 2007.

[22] C. T. Wittwer, G. H. Reed, C. N. Gundry, J. G. Vandersteen, and R. J. Pryor, "High-resolution genotyping by amplicon melting analysis using LCGreen," Clinical Chemistry, vol. 49, no. 6, part 1, pp. 853-860, 2003.

[23] B. Yu, Y. Chen, Q. Wu et al., "The association between single-nucleotide polymorphisms of NCF2 and systemic lupus erythematosus in Chinese mainland population," Clinical Rheumatology, vol. 30, no. 4, pp. 521-527, 2011.

[24] Q. Wu, B. Yu, Y. Chen et al., "Single-nucleotide polymorphisms of MAMDC1 are associated with rash and photosensitivity, but not disease risk, of systemic lupus erythematosus in Chinese mainland population," Clinical Rheumatology, vol. 30, no. 10, pp. 1373-1378, 2011.

[25] E. Sanchez, S. Morales, L. Paco, M. A. Lopez-Nevot, and C. Hidalgo, "Interleukin 12 (IL12B), interleukin 12 receptor (IL12RB1) and interleukin 23 (IL23A) gene polymorphism in systemic lupus erythematosus," Rheumatology, vol. 44, no. 9, pp. 1136-1139, 2005. 


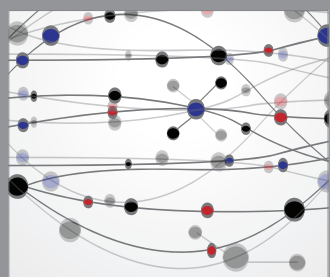

The Scientific World Journal
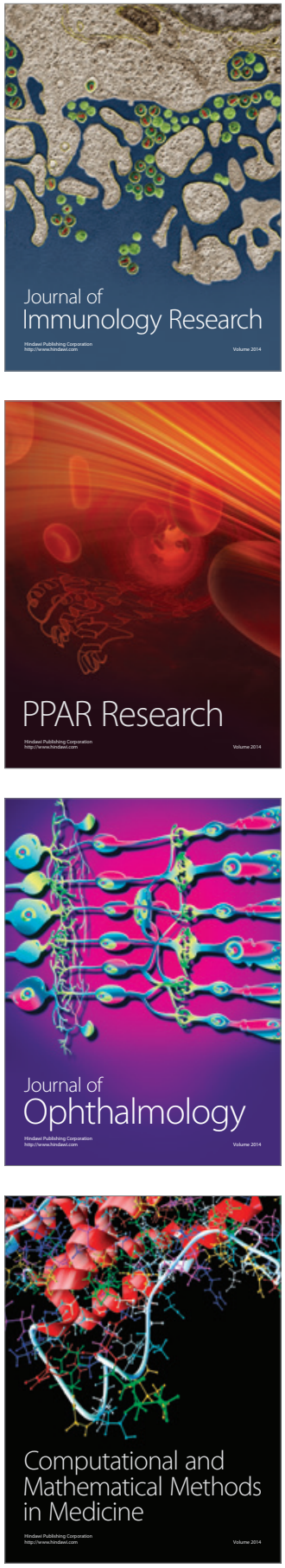

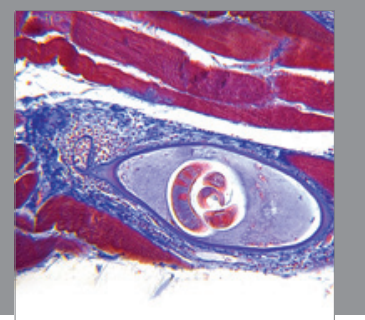

Gastroenterology

Research and Practice
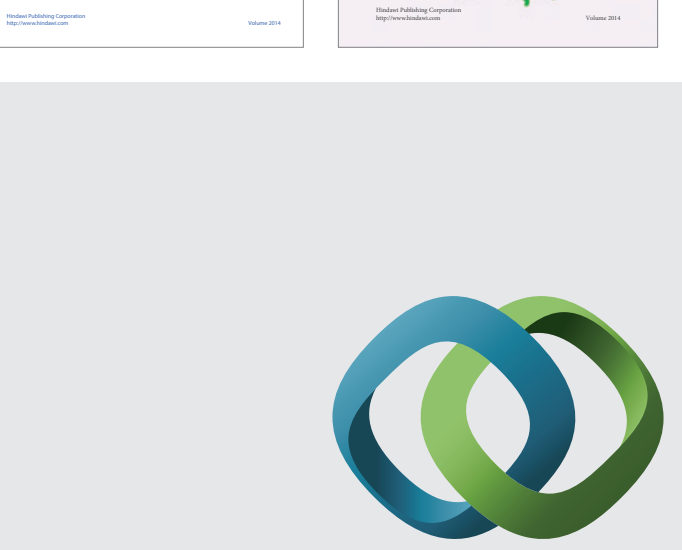

\section{Hindawi}

Submit your manuscripts at

http://www.hindawi.com
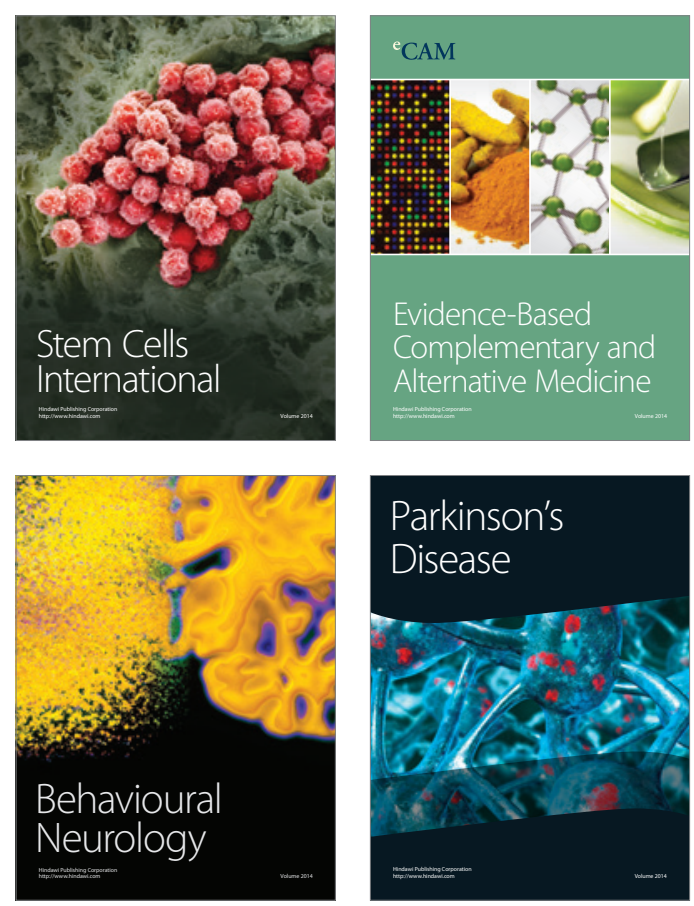

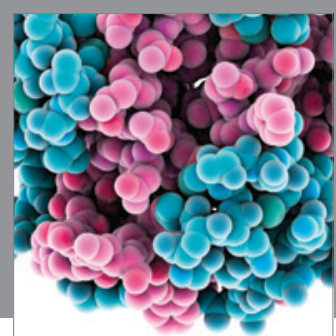

Journal of
Diabetes Research

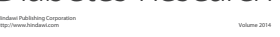

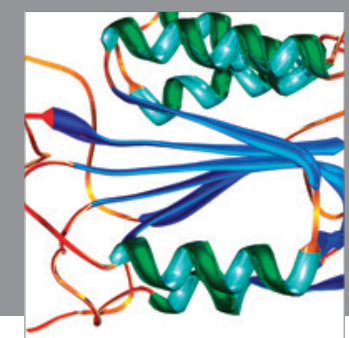

Disease Markers
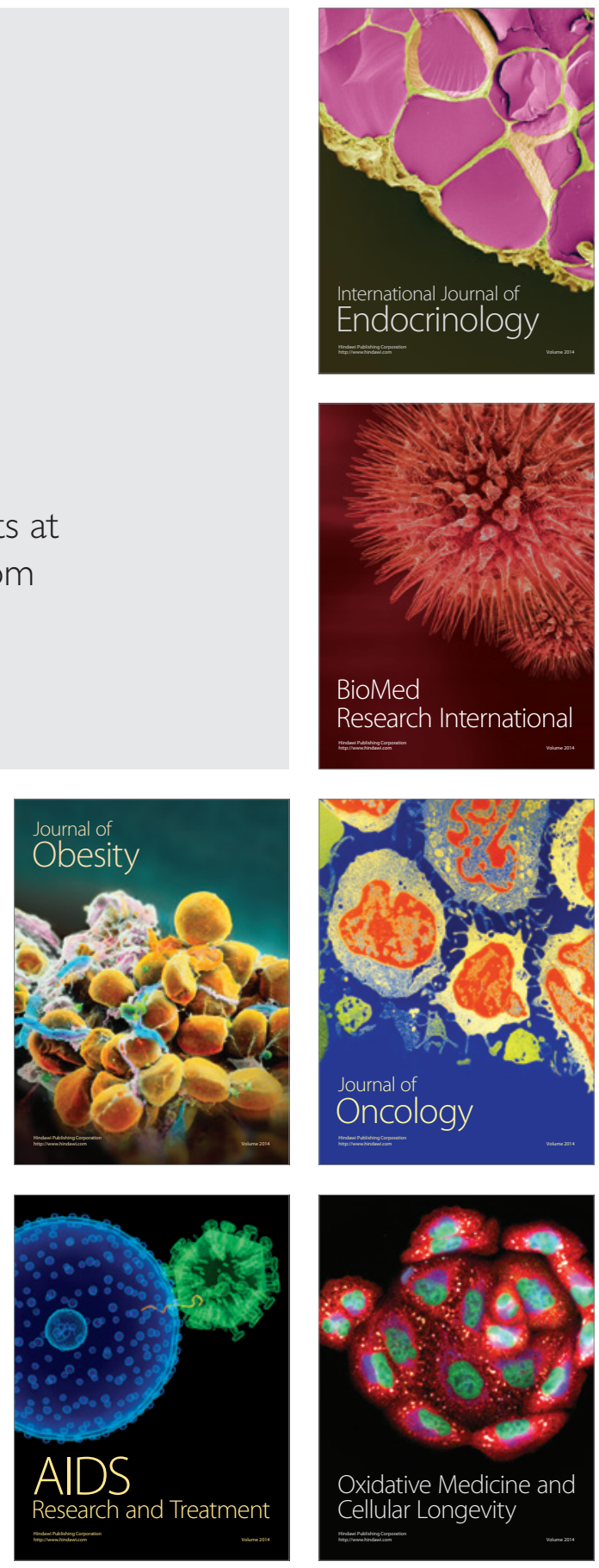